\title{
Prevalence of Malnutrition and Associated Factors Among Children Aged 6-59 Months at Hidabu Abote District, North Shewa, Oromia Regional State
}

\author{
Kebede Mengistu*, Kassahun Alemu and Bikes Destaw
}

Institute of Public Health, College of Medicine and Health Sciences, University of Gondar, Gondar, Ethiopia

\begin{abstract}
Introduction: Malnutrition continues to be a major public health problem in developing countries. It is the most important risk factor for the burden of diseases. In Ethiopia, child malnutrition rate is one of the most serious public health problem and the highest in the world. High malnutrition rates in the country pose a significant obstacle to achieving better child health outcomes.
\end{abstract}

Objective: To assess prevalence of malnutrition and associated factors among children aged 6-59 months at Hidabu Abote district, North shewa, Oromia.

Methods: A community based cross sectional study was conducted on 820 children aged 6-59 months from September 8-23, 2012 at Hidabu Abote district. Multistage sampling method was used to select households. Children were selected from each kebeles by simple random sampling. Anthropometric measurements and structured questioners were used .Data were processed using EPi-info soft ware and exported to SPSS for analysis. Then after, sex, age, height and weight transferred with HHs number to ENA for SMART 2007software to convert nutritional data into Z-scores of the indices; Height-for-age, weight-for-height and weight-for-age. Bivariate and multivariate logistic regressions were used to identify associated factors of malnutrition.

Results: The analysis this study revealed that, $47.6 \%, 30.9 \%$ and $16.7 \%$ of children were stunted, underweight and wasted, respectively. The main associated factors of stunting were found to be child age, family monthly income, children were received butter as pre-lacteal feeding and family planning. Underweight was associated with number of children $\mathrm{HHs}$ and children were received butter as per-lacteal feeding. Treatment of water in $\mathrm{HHs}$ the only variable associated with wasting.

Conclusion and recommendation: From the findings of this study, it is concluded that malnutrition is still an important problem among children aged 6-59 months. Therefore, especial attention should be given on intervention of malnutrition.

Keywords: Malnutrition, Children, Hidabu abote district

\section{Introduction}

\section{Statement of the Problem}

Malnutrition refers to a pathological state resulting from a relative or absolute deficiency or excess of one or more essential nutrients. It is a state of nutrition where the weight for age, height for age and weight for height indices are below -2 Z-score of the NCHS reference. Malnutrition continues to be a major public health problem in developing countries. It is the most important risk factor for the burden of disease causing about 300,000 deaths per year directly and indirectly responsible for more than half of all deaths in children [1]. Health and physical consequences of prolonged states of malnourishment among children are: delay in their physical growth and motor development; lower intellectual quotient (IQ), greater behavioral problems and deficient social skills; susceptibility to contracting diseases [2].

Much of the burden of deaths resulting from malnutrition, estimated to be over half of childhood deaths in developing countries, can be attributed to just mild and moderate malnutrition, varying from $45 \%$ for deaths due to measles to $61 \%$ for deaths due to diarrhea [3]. The majority of studies on child nutritional status have described prevalence of malnutrition among under-five children and analyzed socioeconomic, demographic and cultural factors associated with child malnutrition in SSA [4].

In Ethiopia, child malnutrition is one of the most serious public health problem and the highest in the world [5]. Nationally about $44 \%$ stunted, $29 \%$ underweight and $10 \%$ children were wasted [6]. In
Oromia region prevalence of child malnutrition indicated that $26 \%$ are underweight with $7.8 \%$ severe underweight, $9.7 \%$ of the children are wasted ( $2.8 \%$ severe wasting) and $41.4 \%$ of the children are stunted with $18 \%$ sever stunting [6]. However, the study of prevalence and associated factors of malnutrition among 6- 59 months age children has not been conducted at Hidabu Abote district yet. Therefore, this study designed to assess the prevalence of malnutrition and associated factors among children aged 6-59 months.

\section{Literature Review}

Magnitude of the problems: Malnutrition remains one of the most common causes of morbidity and mortality among children under five children throughout the World [7]. Worldwide, over 10 million children under the age of 5 years die every year from preventable and treatable illnesses despite effective health interventions. At least half of these deaths are caused by malnutrition. Malnourished children

${ }^{*}$ Corresponding author: Kebede Mengistu, Institute of Public Health, College of Medicine and Health Sciences, University of Gondar, Gondar, Ethiopia, Tel: 0913 13-82-68; E-mail: kebme2004@gmail.com

Received June 15, 2013; Accepted July 23, 2013; Published July 25, 2013

Citation: Mengistu K, Alemu K, Destaw B (2013) Prevalence of Malnutrition and Associated Factors Among Children Aged 6-59 Months at Hidabu Abote District, North Shewa, Oromia Regional State. J Nutr Disorders Ther T1: 001. doi:10.4172/2161-0509.T1-001

Copyright: (c) 2013 Mengistu K, et al. This is an open-access article distributed under the terms of the Creative Commons Attribution License, which permits unrestricted use, distribution, and reproduction in any medium, provided the original author and source are credited. 
have lowered resistance to infection; therefore, they are more likely to die from common childhood ailments such as diarrheal diseases and respiratory infections. In addition, malnourished children that survive are likely to suffer from frequent illness, which adversely affects their nutritional status and locks them into a vicious cycle of recurring sickness, faltering growth and diminished learning ability. In developing countries, malnutrition is a major health problem [8].

The burden of malnutrition is much higher in South Asia compared to that in Africa and other parts of the world. The prevalence of underweight and stunting in South Asia has been recorded as 46 and 44 percent, respectively [9]. Chronic malnutrition has been a persistent problem for young children in Sub-Saharan Africa. A high percentage of these children fail to reach the normal international standard height for their age; that is, they are "stunted" In contrast, the percentage of children stunted in Southeast Asia dropped from 52 percent to 42 percent between 1990 and 2006. The number of undernourished (low weight for age)people of all ages in sub-Saharan Africa increased from about 90 million in 1970 to 225 million in 2008 , and was projected to add another 100 million by 2015 , even before the current world food price hikes [10].

A study conducted on influence of socio-economic factors on nutritional status of children in a rural community of osun state, Nigeria revealed that the prevalence rates of underweight, wasting and stunting were $23.1 \%, 9 \%$ and $26.7 \%$ respectively and also prevalence and determinants of malnutrition among Under-five Children of Farming Households in Kwara State, Nigeria results indicate that $23.6 \%$, $22.0 \%$ and $14.2 \%$ of the sample children were stunted, underweight and wasted, respectively $[11,12]$.

Study done on malnutrition among under-five children in Bangladesh revealed that, the high prevalence of stunting and underweight, for instance $42 \%$ and $40 \%$ of under-five children were stunted and underweighted, respectively [13]. Also study conducted nutritional status of under- five children in Mongolia also showed that, the prevalence of stunting, wasting and underweight were $15.6 \%, 1.7 \%$ and $4.7 \%$,respectively [14].

A cross-sectional study conducted in Belahara VDC of Dhankuta district in Nepal located in South Asia, the prevalence of underweight, stunting and wasting were $27 \%, 37 \%$ and $11 \%$, respectively [15]. The prevalence of children under five years with acute malnutrition in Southern Sudan is one of the highest in the world approximately one out of every five children (22\%) suffers from moderate to severe acute malnutrition (wasting). The prevalence of acute malnutrition among this age population in Southern Sudan is almost twice as high as in other parts of Sudan and also study conducted in a decertified area of Sudan - Alrawakeeb valley revealed that the prevalence of malnutrition among these children is very high $(27.5 \%$ were severely malnourished and $35 \%$ suffered from either mild or moderate malnutrition $[16,17]$.

According to research conducted in pre-school children in a rural area of western Kenya reveled that, the prevalence of stunting, underweight and wasting were $30 \%, 20 \%$, and $4 \%$, respectively [18].

Although a cross-sectional survey conducted in a rural locality called Gumbrit, the overall prevalence of malnutrition in the community was high with $28.5 \%$ of the children being underweight, $24 \%$ stunted and $17.7 \%$ wasted .Similarly, study done at Beta-Israel community revealed that, the prevalence of stunting, Underweight and wasting were $37.2 \%, 14.6 \%$, and $4.5 \%$, respectively. Moreover, severe stunting, severe underweight and severe wasting were seen in $14.8 \%$, $2.9 \%$, and $0.5 \%$ of the Children respectively $[19,20]$.
A community based cross-sectional survey conducted West Gojam zone revealed that $49.2 \%$ children were found to be under-weight , $43.2 \%$ of the children under age five were suffering from chronic malnutrition and $14.8 \%$ acutely malnourished [21]. The cross sectional survey conducted rural communities of Tigray region also revealed that, the levels of stunting, under weight and wasting were $42.7 \%$, $38.3 \%$ and $13.4 \%$, respectively [22].

A cross sectional study conducted in Aynalem village in Tigray region, the overall prevalence of stunting, underweight and wasting were $45.7 \%, 43.1 \%$ and $7.1 \%$, respectively [23]. According to research conducted in Gimbi district Oromia region indicated that, $32.4 \%$ stunted, $23.5 \%$ underweight and $15.9 \%$ of the children were wasted. Prevalence of severe stunting, severe underweight and severe wasting respectively were $15.7 \%, 8.0 \%$ and $5.7 \%$ [24].

A community-based cross-sectional study conducted in rural kebeles of Haramaya district although revealed that, the prevalence of stunting, underweight, and wasting were $42.2 \%, 36.6 \%$, and $14.1 \%$, respectively. In addition, the proportion of the prevalence of malnutrition by its level of severity indicated that $19.9 \%$ were severely stunted, $16.6 \%$ were severely underweight and $3.9 \%$ were severely wasted [25]

Associated factors: The causes of malnutrition are numerous and multifaceted. These causes are intertwine with each other and are hierarchically related. The most immediate determinants are poor diet and disease which are themselves caused by a set of underlying factors; household food security, maternal/ child caring practices and access to health services and healthy environment. These underlying factors themselves are influenced by the basic socio-economic and political conditions [1].

Study conducted on malnutrition among under five children in Bangladesh revealed that household economic status, mother's education, father's education, mother's antenatal visit (s), mother's age at birth and mother's BMI are the most significant factor /determinant s of child's malnutrition [13].

As study on influence of socio-economic factors on nutritional status of children in a rural community of osun state, Nigeria, Children of mothers who were not educated beyond secondary school level had one and a half to two times the prevalence rate of stunting. On the other hand, children of mothers with post secondary education were apparently more often affected by wasting than those with less educated mothers but there was no consistent trend in the pattern of wasting or stunting with respect to paternal educational level. Low maternal income and overcrowding were associated with higher prevalence of wasting. However no association was found between the source of drinking water or social class and malnutrition [15]. Study conducted on prevalence and determinants of malnutrition among Under-five Children of Farming Households in Kwara State, Nigeria, malnutrition were significant associated gender and age of child, education and body mass index of mother, calorie intake of the households, access to clean water and presence of toilet in the households [16].

According research conducted in Belahara VDC of Dhankuta district in Nepal located in south Asia, poor socioeconomic status was found risk factors for both stunting and underweight, Children reared in the jointly family were found less like to be stunted than those in nuclear family. Also ethnic group and age of mothers at pregnancy seems to have significance association with stunting but maternal education not associated. Nevertheless, study conducted in a decertified area of Sudan - Alrawakeeb valley revealed that maternal education was 
found to be the strongest factor associated with malnutrition among under five children [15,17].

Among the socio-economic variables included in the study rural locality of Gumbrit, the only family income was significantly associated with malnutrition [19]. Study conducted at Beta-Israel also show that the main contributing factors for under-five malnutrition were found to be sex of the child, child's age, diarrhea episode, deprivation of colostrums, duration of breastfeeding, pre-lacteal feeds, type of food, age of introduction of complementary feeding and method of feeding [20].

Malnutrition varies from country to country depending on economic, ecological, social, and other factors. In Ethiopia at present the most serious nutritional problems are mainly due to low intake of foods in general. The problem is more severe among children aged 1-3 years who suffer from Kwashiorkor and Marasmus (4\%) and under weight (60\%). Any change in income or income from influence of the nutritional status at the household and individual levels. The effect of income is measured by expenditure on food which reflects a household's income and resources [26]. Study conducted by Bayesian Approach to identify predictors of nutritional status in Ethiopia, the main predictors of children nutritional status were place of residence, maternal education, occupation of mother, Preceding birth interval, source of water drinking, age of child, sex of child, Mother's BMI and age of mothers [27].

Study conducted in rural Tigray region revealed that, a very high proportion of the mothers $(80 \%)$ initiated feeding of newborns with pre-lacteal feeds primarily butter or water. Child age, maternal anthropometric characteristics, inadequate complementary foods, and area of residence were the main contributing factors to child malnutrition [22]. The prevalence of stunting and underweight were significantly associated with the age group of children in Aynalem village in Tigray region. Both highest prevalence of stunting and underweight were observed among the age group of 12-24 months whereas the lowest prevalence of stunting, wasting, and underweight were observed among the age 0-6 months age group [23].

The main important associated factors of under nutrition include the education, income, and nutritional situation of the parents, access to clean water and sanitation, access to primary health care, sex and age of child. Factors that are contributing to malnutrition may differ among regions, communities and over time. Identifying the underlying causes of malnutrition in a particular locality is important to solve the nutritional problems. Various studies have been made and conclusions were reached by different scholars in the past regarding predictors of health and nutritional status. Survey of available literature indicated that factors like knowledge of health practices and caring level, educational level of parents, access to or interactions of age of the child have strong effect on household and community variables in which the child grows up [28].

Study conducted in Gimbi district show that the main associated factors of wasting were childhood illness indicated by fever, low household income and maternal lack of education. Low birth size of children, paternal lack of education, maternal lack of decision making on use of money and lack of animals were associated with chronic malnutrition (stunting). ARI in children and lack of windows of houses are the most important factors of underweight [25] (Figure 1).

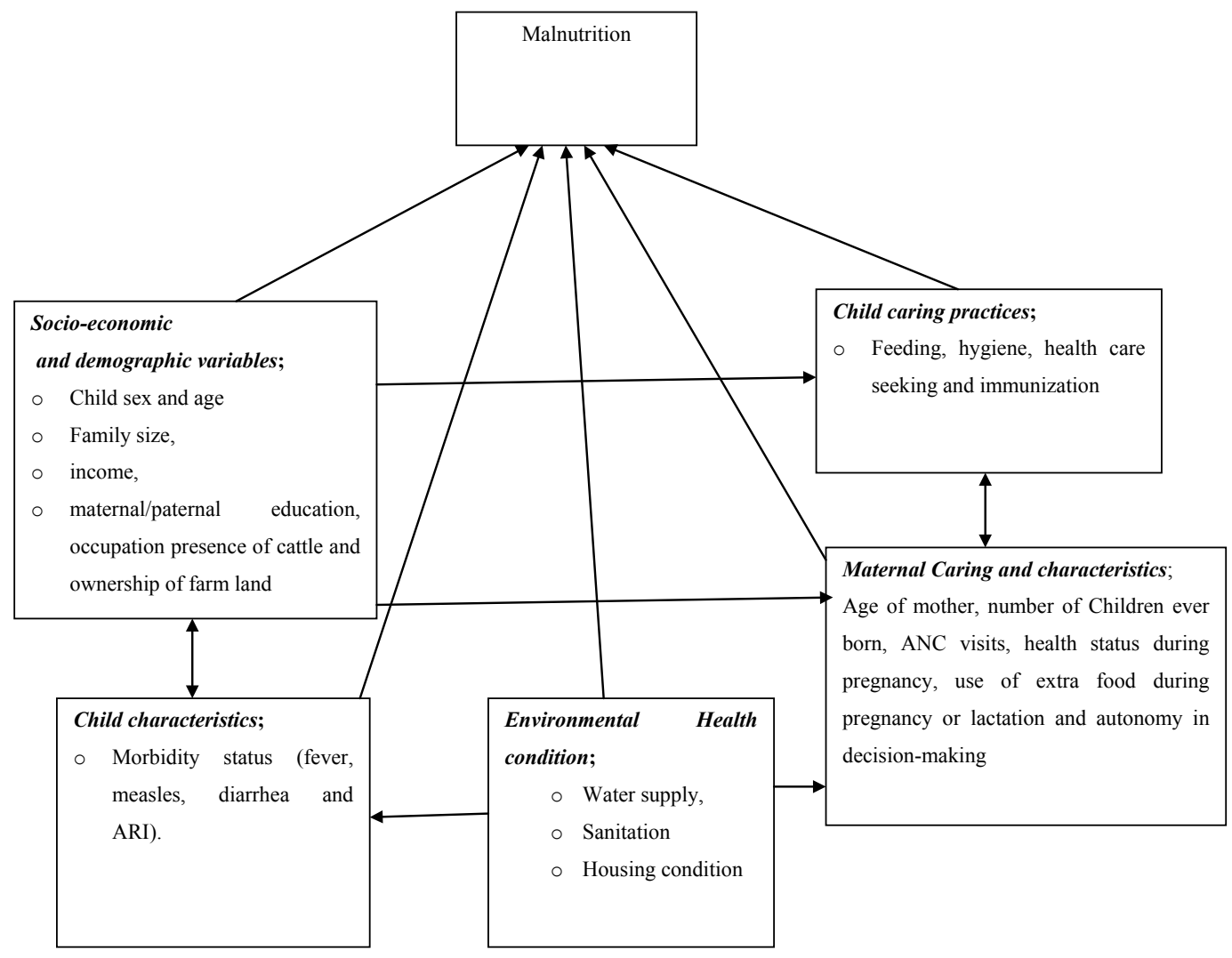

Figure 1: Conceptual frame work of malnutrition. 
Citation: Mengistu K, Alemu K, Destaw B (2013) Prevalence of Malnutrition and Associated Factors Among Children Aged 6-59 Months at Hidabu Abote District, North Shewa, Oromia Regional State. J Nutr Disorders Ther T1: 001. doi:10.4172/2161-0509.T1-001

\section{Justification}

Malnutrition is one of the main health problems facing children in under five age group in developing countries.

The prevalence of malnutrition imposes significant costs on the Ethiopian economy as well as society. The high mortality due to malnutrition leads to the loss of the economic potential of the child .It affects children in many ways, predisposing them to different infectious diseases, psychosocial maldevelopment, and cognitive deficiencies.

The prevalence of malnutrition in Ethiopia is relatively well documented, but not specific to the regions, localities and residence so far. It is also vary among regions, localities and residence and limited data is available in study area. Study conduct in other districts is not address the main associated factors of malnutrition.

Therefore, this study was design to assess the prevalence of malnutrition and associated factors among children aged 6-59 months can be used as a reference in priority setting and designing effective nutritional programs at Hidabu Abote district.

\section{Objective}

\section{General Objective}

To assess prevalence of malnutrition and associated factors among children aged 6-59 months at Hidabu Abote district, North shewa, Oromia region, Ethiopia, 2012.

\section{Specific Objectives}

To determine prevalence of malnutrition among children aged 6-59 months at Hidabu Abote.

To identify associated factors of malnutrition among children aged 6-59 months at Hidabu Abote.

\section{Methods}

\section{Study Design}

A community based cross-sectional study was conducted to assess the prevalence of malnutrition and associated factors among children aged 6- 59 months.

\section{Study Area and Period}

The study was conducted from September 8-23, 2012 at Hidabu Abote district. Hidabu Abote woreda is one of the 14 woredas of North Shewa Zone of Oromia Regional State and located $34 \mathrm{kms}$ from the zonal capital Fitche, and 146 from Finfinne. The woreda is divided in to 20 kebeles of which 19 of them are peasant associations acting as rural administrative units and one urban administrative unit with 92,603 total populations, 20,406 $\mathrm{HHs}$ and 16,064 under five children [29]. Hidabu Abote woreda has proximity with Dera in north, Wero Jarso in the west, Kuyu in the south and south west and Degem in the north east, east and south east. The total area of the woreda is about 485.84 sq.kms, sharing about $4.05 \%$ of the zonal area.

\section{Source and Study Population}

Source populations were all children aged 6-59 months living in the district and the study populations were children of aged 6-59 months randomly selected and included in the study.

\section{Inclusion and exclusion criteria}

Inclusion criteria: The inclusion criteria of study participants were children aged 6-59 months who live in Hidabu Abote district.
Exclusion criteria: The study participants who were seriously ill were not included in the study.

\section{Sample Size Determination and Sampling Techniques}

Sample size determination: The sample size was determine using a single proportion formula by using $41.4 \%$ of prevalence of stunting in Oromia region (6),95\% confidence interval(CI), marginal of error $5 \%$ and $10 \%$ non response rate are added to the total sample size is computed.

A Z-value of 1.96 used at $95 \% \mathrm{CI}$ and $\mathrm{d}$ of $5 \%$. ( $\mathrm{n}=$ sample size, $\mathrm{p}=$ prevalence, $\mathrm{d}=$ margin of error).

$$
\begin{aligned}
& \mathrm{n}=\mathrm{Z}^{2} \mathrm{p}(1-\mathrm{p})=\left(1.96^{2} \mathrm{x} 0.414\right)(1-0.414)=373 \\
& \mathrm{~d}^{2} 0.05^{2}
\end{aligned}
$$

So with adjustment for non-response ( $10 \%$ contingency) $\mathrm{n}=$ $(373+37)=410$, and again multiplied by design effect 2 , the final sampling size was 820 children.

The sampling technique and procedures: Multistage sampling technique followed by simple random sampling was used to select children from households. From 19 rural kebeles, six kebeles were selected by simple random sampling (lottery method). Study participants/households/care takers were allocated to selected kebeles by proportionate allocation and from each selected kebeles study participants were selected by simple random sampling (table of random numbers) based on frame existing in health posts (Figure 2).

Formula used to calculate sample size of each selected kebeles:

$n i=\left(n^{*} \mathrm{Ni}\right) / \mathrm{N}$ where $\mathrm{ni}=$ sample size of each selected kebeles

$\mathrm{n}=$ total sample size

$\mathrm{Ni}=$ total number of household in each selected kebeles

$\mathrm{N}=$ total number of household in all selected kebeles

\section{Study Variables}

Dependent variable: Malnutrition indicated by stunting, wasting and underweight

Independent variables: Five categories of factors were assessed as independent variables;

$>$ Socio-economic and demographic variables; Head of HHs,marital status, ethinicity,religion,family size, income, education ,occupation, ownership of livestock and farm land.

Child characteristics; Age, Sex, birth order, place of delivery, gestational age, types of birth, breastfeeding status and morbidly status (fever, measles, diarrhea and ARI).

$>$ Child caring practices; Feeding, hygiene, health care seeking and immunization

> Maternal characteristics; age, number of children ever born, ANC visits, extra food during pregnancy/lactation, health status during pregnancy, use of extra food during pregnancy or lactation and autonomy in decision-making on use of money.

$>$ Environmental Health condition; Water supply, sanitation and housing condition.

\section{Operational Definitions}

Acute Respiratory Infection (ARI): A child with cough, fast breathing or difficulty in breathing and fever. 


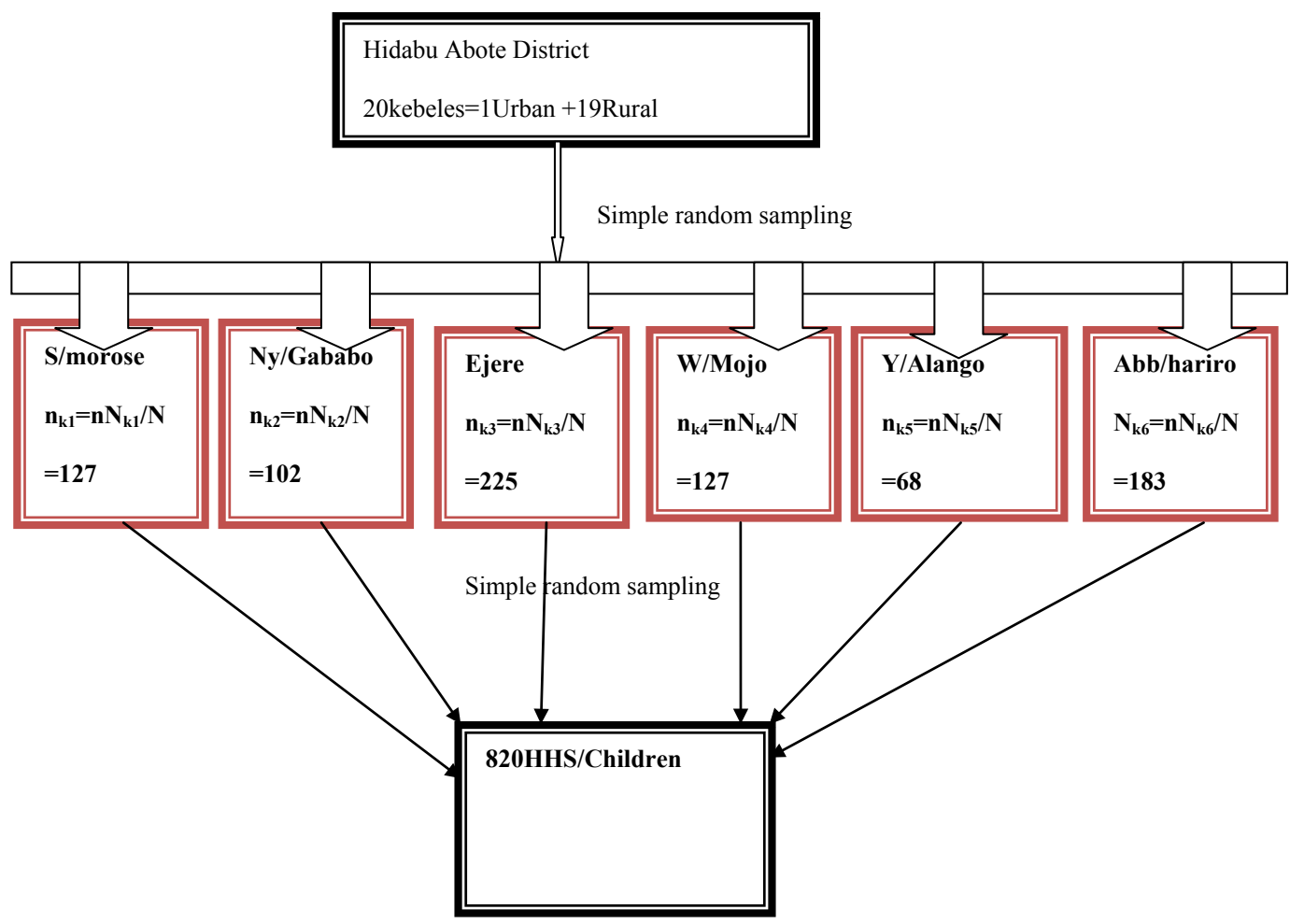

\section{Key notes}

$\mathrm{n}_{\mathrm{k}}=$ number of sample for each kebeles by proportionate allocation

$\mathrm{n}=$ Sample size of study $/ 820 /$

$\mathrm{N}_{\mathrm{K}}=$ total number of Household/study participants in each selected kebeles

o (S/morose(828),Ny/gababo(736),Ejere(1616),W/Mojo(913), Y/alango(488),Abb/hariro(1318))

$\mathrm{N}=$ total number of Household/participants in all selected kebeles/5,899/

Figure 2: Schematic presentation of sampling procedure.

Anthropometry: Measurement of the variation of physical dimensions and the gross composition of the human body at different age levels and degrees of nutrition by weight-for-age, height-for-age and weight-for-height [30].

Complementary food: Foods which are required by the child, after six months of age, in addition to sustained breastfeeding.

Diarrhea: Diarrhea is defined for a child having three or more loose or watery stools per day.

Family size: refers total number of people living in a house during the study period.

Fever: A child with elevated body temperature than usual.

Income: It is periodical monthly earning from one's business, lands, work, investment etc.

Malnourished: A child was labeled as malnourished if any of the nutritional assessment indices weight for height, weight for age, or height for age is abnormal [30].

Measles: A child with more than three signs of the following is considered having measles: fever, and skin rash, runny nose or red eyes, and/or mouth infection, or chest infection.

Stunting: A child was defined as stunted if the height for age index was found to be below -2 SD of the median of the standard curve. Severe stunting was diagnosed if it was below -3 SD [30].
Underweight: Refers to a deficit and is defined as underweight below the -2 SD from the NCHS/WHO reference of the median of the standard curve. A severely underweight was diagnosed if it was below $-3 \mathrm{SD}[30]$.

Wasting: Nutritional deficient state of recent onset related to sudden food deprivation or mal-absorption utilization of nutrients which results weight loss, weight-for-height below-2SD from the NCHS/WHO median value. Severe wastage was diagnosed if it was below -3 SD [30].

\section{Data Collection Procedures}

Data were collected using structured questionnaire and anthropometric measurement. Eleven data collectors who were able to communicate in Oromiffa were recruited from health centers and health posts in the district. Training was provided for data collectors and supervisor for two days.

Interview was conducted with mothers/care takers of the children to fill the questionnaire. In HHs with more than one children of age between 6-59 months, one child was selected randomly by lottery method.

Anthropometric data: The anthropometric data were collected using the procedure stipulated by the WHO (2006) for taking anthropometric measurements. Before taking anthropometric data for children; their age should first determined in order to ensure the target population. A local event was used to establish the birth period. The 
mothers were asked whether the child was born before or after certain major events until a fairly accurate age is pinpointed. If age cannot be determined accurately a height of $65-110 \mathrm{~cm}$ was considered as proxy indicators [30].

Height/length measurement: Body length of children age up to 23 months was measured without shoes and the height was read to the nearest $0.1 \mathrm{~cm}$ by using a horizontal wooden length board with the infant in recumbent position. However, height of children 24 months and above was measured using a vertical wooden height board by placing the child on the measuring board, and child standing upright in the middle of board. The child's head, shoulders, buttocks, knees and heels touching the board.

Weight measurement: Weight was measured by electronic digital weight scale with minimum/lightly/clothing and no shoes. Calibration was done before weighing every child by setting it to zero. In case of children age below two years, the scale was allowed weighing of very young children through an automatic mother-child adjustment that was eliminated the mother's weight while she standing on the scale with her baby.

Oedema was checked and noted on data sheet because children with oedema were severely malnourished. In order to determine the presence of oedema, normal thumb pressure was applied to the two feet for three seconds whether a shallow print or pint remains on both feet when the thumb is lifted.

To identify retrospective morbidity of children, mothers were asked about any occurrence of illness during the past two weeks. Enumerators probe to confirm nature of illness based on operational case definition and also asked to identify occurrence of measles in the past one year.

Vaccination status of children were checked by observing immunization card and if not available mothers were asked to recall it. BCG vaccination was checked by observing scar on right (also left) arm.

\section{Data Quality Management}

Structured questionnaire was prepared in English and translated into Oromiffa language and retranslated back to English by language experts to increase measurement accuracy and for field work purpose. Pre-test of the questionnaire was done on 5\% of sample size in similar area, which was not include in study before the actual data collection to see for the accuracy of responses and to estimate time needed. The scales indicators were checked against zero reading after and before weighing every child. On daily basis collected information was reviewed and possible errors were returned to the collectors for correction.

\section{Data Processing and Analysis}

First the data were checked for completeness and consistency. Then it was coded and entered in the computer using EPI-INFO3.5.1 software and then sex, age, height and weight transferred with HHs number to ENA for SMART 2007software to convert nutritional data into Z-scores of the indices; $\mathrm{H} / \mathrm{A}, \mathrm{W} / \mathrm{H}$ and (W/A) using NCHS reference population standard of WHO. Then, the data were exported to SPSS version 16 for analysis; descriptive summary using frequencies, proportions, graphs and cross tabs was used to present study results.

Analysis was carried out at two. Firstly, a bivariate analysis was performed to determine the association of malnutrition and associated factors. Statistical association was checked by $95 \%$ confidence interval and crude odd ratio. Secondly, the significant variables ( $\mathrm{p}$-value < 0.2 ) observed in bivariate analysis were subsequently included in multivariate analysis. Finaly, 95\% confidence interval and adjusted odd ratio were checked and the significance variables were taken as associated factors of malnutrion.P-value less than $0.05,95 \% \mathrm{CI}$ and odd ratio were considered as statistically significant.

\section{Ethical Consideration}

Ethical clearance was obtained from Ethical Review Board of University of Gondar, College of Medicine and Health sciences, Institute of Public Health and it was also got granted from Oromia Regional Health Bureau, North Shewa Zonal Health Department, Health office of Hidabu Abote district and kebele administration units. Verbal consent from parents/care taker of study subjects was obtained and the objective of the study was explained to them.

Privacy and confidentiality of collected information was ensured at all level. Two sick children and one severely malnourished with problems of shortage foods were referred to nearest health facilities and health/nutritional advice is also given to parents/care taker.

\section{Dissemination and Utilization of Results}

The result of the study was presented to Institute of Public Health, College of Medicine and Health sciences, University of Gondar as part of Masters of Science in Applied Human Nutrition thesis. Although this finding will be shared to Oromia Regional Health Bureau, North Shewa Zonal Health Department, Hidabu Abote district health office and respective kebele administrations as well to all stakeholders working on nutritional interventions for appropriate nutritional intervention strategy. Efforts will be made to present the results on scientific conferences and peer reviewed journal publications will be considered.

\section{Results}

\section{Demographic and Socio-Economic Characteristics}

From the total planned study subjects, complete response was obtained for $820(100 \%)$. As indicated in Table 1, 727(88.7\%) households were headed by male and 716(87.3\%) respondent were married.

Majority of respondents were Oromo ethnic group 806 (98.3\%) and $810(98.8 \%)$ were Orthodox. Out of the respondents, 407(50.9\%) had average and less than five family size while 403(49.1\%) of households have more than five and $635(77.4 \%)$ of HHs were had one under five years children.

Concerning educational status 538(65.6\%) of mothers and $438(53.4 \%)$ of fathers cannot read and write. About $572(69.8 \%)$ of mothers and 585(71.3\%) fathers were farmer. Although, 618(75.4\%) of households earn monthly income of less than 750birr and 709(86.1\%) of them were decision making on use of money made both jointly (husband and wife).

Regarding livestock, 562(68.5\%) of HHs were had livestock and out of them $40 \%$ were had $1-5$ and $7.4 \%$ were had more than 10 livestocks. On the other hand $499(60.9 \%)$ of households were had farm land and out of them 344(42\%) were had more than 0.5 Hectare.

\section{Characteristics and Caring Practices of Children}

Child characteristics: A total of 820 children aged 6-59 months within six kebeles (Sire Morose,Welu Mojo, Nya'a Gababo, Ejere,Yaya Alango and Hariro Abbadho) selected from Hidabu Abote district were included, from the total $410(50.0 \%)$ were males and $410(50.0 \%)$ were females (Table 2). 
Citation: Mengistu K, Alemu K, Destaw B (2013) Prevalence of Malnutrition and Associated Factors Among Children Aged 6-59 Months at Hidabu Abote District, North Shewa, Oromia Regional State. J Nutr Disorders Ther T1: 001. doi:10.4172/2161-0509.T1-001

Page 7 of 15

Among the total children aged 6-59 months, 77(9.4\%),172(21\%),184(22.4\%), 185(22.6\%) and 202(24.6\%) children were found in the age groups of 6-11, 12-23, 24-35, 36-47 and 48-59 months, respectively. The mean age of children was 32.1 with SD of 14.9.

From the total children,652(79.5\%) of children were delivered at home and 168(20.5\%) children were delivered at health facilities. Out of the children were delivered at health facilities and home,33(4\%) ,549(67\%) and 238(29\%) of children were born less than nine months, at nine months and greater than nine months, respectively. Out of these $23(2.8 \%)$ of children were twin.

Regarding breastfeeding status,484(59\%) of children were still breast feeding at the time of survey and others not breastfeeding due to refusal of children, maternal pregnancy, maternal health problems and lack of milk by mothers.

As indicated table 2 about the prevalence of common childhood illness, out of the 820 children,212(25.9\%) of children had diarrhea in last two weeks before study conducted. Out of children who had

\begin{tabular}{|c|c|c|c|}
\hline \multicolumn{2}{|l|}{ Characteristics } & \multirow{2}{*}{$\begin{array}{l}\text { Frequency } \\
727\end{array}$} & \multirow{2}{*}{\begin{tabular}{|l|} 
Percent \\
88.7 \\
\end{tabular}} \\
\hline Head of $\mathrm{HHc}$ & Male & & \\
\hline neau or nats & Female & 93 & 11.3 \\
\hline \multirow{3}{*}{ Marital status } & Married & 716 & 87.3 \\
\hline & Divorced & 65 & 7.9 \\
\hline & Others $^{a}$ & 36 & 4.8 \\
\hline \multirow{2}{*}{ Ethnicity } & Oromo & 806 & 98.3 \\
\hline & Amhara & 14 & 1.7 \\
\hline \multirow{2}{*}{ Religion } & Orthodox & 810 & 98.8 \\
\hline & Others $^{b}$ & 10 & 1.2 \\
\hline \multirow{2}{*}{ Family size } & $\leq 5$ & 417 & 50.9 \\
\hline & $>5$ & 403 & 49.1 \\
\hline \multirow{2}{*}{ HHs with under $5 y r s$ children } & 1 & 635 & 77.4 \\
\hline & $2-3$ & 185 & 22.6 \\
\hline \multirow{5}{*}{ Maternal Education } & Can't read and write & 538 & 65.6 \\
\hline & Can read and write(Informal education) & 16 & 2.0 \\
\hline & Primary education & 215 & 26.2 \\
\hline & Secondary education & 21 & 2.6 \\
\hline & Higher education & 30 & 3.7 \\
\hline \multirow{5}{*}{ Paternal education } & Can't read and write & 438 & 53.4 \\
\hline & Can read and write & 37 & 4.5 \\
\hline & Primary education & 270 & 32.9 \\
\hline & Secondary education & 26 & 3.2 \\
\hline & Higher education & 49 & 6.0 \\
\hline \multirow{4}{*}{ Occupation of mother } & Housewife only & 59 & 7.2 \\
\hline & Farmer & 572 & 69.8 \\
\hline & Merchant/Trade & 111 & 13.5 \\
\hline & Others ${ }^{c}$ & 78 & 9.5 \\
\hline \multirow{4}{*}{ Occupation of husband } & Farmer & 585 & 71.3 \\
\hline & Gov't employee & 60 & 7.3 \\
\hline & Merchant/Trade & 101 & 12.3 \\
\hline & Others $^{d}$ & 74 & 9.0 \\
\hline \multirow{3}{*}{ Monthly income(In Birr) } & $<750$ & 618 & 75.4 \\
\hline & $750-1500$ & 163 & 19.9 \\
\hline & $>1500$ & 39 & 4.8 \\
\hline \multirow{4}{*}{ Decision making on use of money } & Mainly spouse & 91 & 11.1 \\
\hline & Mainly Husband & 14 & 1.7 \\
\hline & Only husband & 9 & 1.1 \\
\hline & Both jointly & 709 & 86.1 \\
\hline \multirow{2}{*}{ Ownership of livestock } & Yes & 562 & 68.5 \\
\hline & No & 258 & 31.5 \\
\hline \multirow{3}{*}{ Livestock per household } & $1-5$ & 328 & 40.0 \\
\hline & $6-10$ & 173 & 21.1 \\
\hline & $>10$ & 61 & 7.4 \\
\hline \multirow{2}{*}{ Ownership of land } & Yes & 499 & 60.9 \\
\hline & No & 321 & 39.1 \\
\hline \multirow{2}{*}{ Land by hectare per $\mathrm{HH}$} & $\leq 0.5$ Hectare & 155 & 18.9 \\
\hline & $>0.5$ Hectare & 344 & 42 \\
\hline
\end{tabular}

aWidowed, Separated 'Muslim, protestant 'Private org.employee, gov't employee, student, 'Private employee, Daily laborer, student

Table 1: Demographic and socio-economic characteristics of children families at Hidabu Abote district, North shewa zone, September 2012(N=820). 
Citation: Mengistu K, Alemu K, Destaw B (2013) Prevalence of Malnutrition and Associated Factors Among Children Aged 6-59 Months at Hidabu Abote District, North Shewa, Oromia Regional State. J Nutr Disorders Ther T1: 001. doi:10.4172/2161-0509.T1-001

Page 8 of 15

\begin{tabular}{|c|c|c|}
\hline Characteristics & Frequency & Percent \\
\hline \multicolumn{3}{|l|}{ Child sex } \\
\hline Male & 410 & 50.0 \\
\hline Female & 410 & 50.0 \\
\hline \multicolumn{3}{|l|}{ Child age(In months) } \\
\hline $6-11$ & 77 & 9.4 \\
\hline $12-23$ & 172 & 21.0 \\
\hline $24-35$ & 184 & 22.4 \\
\hline $36-47$ & 185 & 22.6 \\
\hline $48-59$ & 202 & 24.6 \\
\hline \multicolumn{3}{|l|}{ Place of delivery } \\
\hline Home & 652 & 79.5 \\
\hline Health facility & 168 & 20.5 \\
\hline \multicolumn{3}{|l|}{ Gestational Age at birth } \\
\hline Less than 9 months & 33 & 4.0 \\
\hline At 9 months & 549 & 67.0 \\
\hline Greater than 9 months & 238 & 29.0 \\
\hline \multicolumn{3}{|l|}{ Types of birth } \\
\hline Single & 797 & 97.2 \\
\hline Twin & 23 & 2.8 \\
\hline \multicolumn{3}{|l|}{ Still breastfeed child } \\
\hline Yes & 484 & 59.0 \\
\hline No & 336 & 41.0 \\
\hline \multicolumn{3}{|c|}{ Reason for not feed breast $(n=336)$} \\
\hline Maternal health problems & 45 & 5.5 \\
\hline Refusal of child & 212 & 25.9 \\
\hline Maternal pregnancy & 79 & 9.6 \\
\hline \multicolumn{3}{|l|}{ Diarrhea } \\
\hline Yes & 212 & 25.9 \\
\hline No & 608 & 74.1 \\
\hline \multicolumn{3}{|l|}{ Frequency of diarrhea per year } \\
\hline 1 episode & 40 & 4.9 \\
\hline 2 episode & 50 & 6.1 \\
\hline 3-4episode & 102 & 12.4 \\
\hline$\geq$ 5episode & 20 & 2.4 \\
\hline \multicolumn{3}{|l|}{ Fever } \\
\hline Yes & 55 & 6.7 \\
\hline No & 765 & 93.3 \\
\hline \multicolumn{3}{|l|}{ ARI } \\
\hline Yes & 48 & 5.9 \\
\hline No & 772 & 94.1 \\
\hline \multicolumn{3}{|l|}{ Measles } \\
\hline Yes & 19 & 2.3 \\
\hline No & 801 & 97.7 \\
\hline
\end{tabular}

Table 2: Characteristics of children age 6-59 months at Hidabu Abote District North shewa zone, Oromia, September 2012( $n=820)$.

diarrhea,102(12.4\%) of children had 3 to 4 episode of diarrhea per year and $23(2.8 \%)$ had five or more than episodes per a year. Also, $55(6.5 \%)$, $48(5.9 \%)$ and $19(2.3 \%)$ of children had fever, ARI and measles, respectively.

Characteristics of child caring practices: As indicated in table 3 , from the total of children, 546(66.6\%) of children were initiated breastfeeding practice immediately after birth. In addition to initiation of breastfeeding practice, 372(45.4\%) children were received prelactation of food or fluids like Butter 247 (30.1\%) and sugar with water 125(15.2\%). 770(93.9\%) children were exclusively breastfeed until six months.

About $453(48.7 \%)$ of children started complementary feeding at the age of 6 months. However, 31(3.8\%) of children not started complementary feeding in addition to breastfeeding last $48 \mathrm{hrs}$ before survey but others were started additional food and out of them $227(27.7 \%)$ were feeding three times per day.

Regarding methods of feeding, majority of children who were started complementary feeding were used by cup $230(28 \%)$ and $95.6 .0 \%$ of care giver/mothers were washed their feeding materials of children immediately after feeding.

Concerning immunization status and vitamin A supplementation, 785(95.7\%) of children were immunized and 766(93.3\%) of children were supplemented with vitamin A. However, only 35(4.3\%) and $54(6.6 \%)$ children were neither immunized and nor supplemented with vitamin $\mathrm{A}$.

\section{Maternal Characteristics}

As showed Table 4 , mean ( \pm SD) age of mothers were $28.9( \pm 6 \mathrm{SD})$ years and mean age of first and youngest children birth were 18.4( $\pm 3.2 \mathrm{SD})$ and $26.1( \pm 5.9 \mathrm{SD})$, respectively. Majority $459(56.0 \%)$ of mothers were in age group between $20-29$ years. About $512(62.4 \%)$ of mothers gave first children birth below 18 years of age.

\begin{tabular}{|c|c|c|}
\hline Characteristics & Frequency & Percent \\
\hline \multicolumn{3}{|c|}{ Initiation of breastfeeding of child } \\
\hline Immediately & 546 & 66.6 \\
\hline After1 to $24 \mathrm{hrs}$ & 22 & 2.7 \\
\hline After a day & 252 & 30.7 \\
\hline \multicolumn{3}{|c|}{ Child received pre-lactation food/fluid } \\
\hline Yes & 372 & 45.4 \\
\hline No & 448 & 54.6 \\
\hline \multicolumn{3}{|c|}{ Pre-lactation food/fluids kind } \\
\hline Water with sugar & 102 & 12.4 \\
\hline Butter & 270 & 32.9 \\
\hline \multicolumn{3}{|c|}{ Age complementary feeding started(In months) } \\
\hline $1-2$ & 4 & 0.5 \\
\hline $4-5$ & 17 & 2.1 \\
\hline 6 & 399 & 48.7 \\
\hline $7-12$ & 33 & 4.0 \\
\hline \multicolumn{3}{|c|}{ Complementary food last $48 \mathrm{hrs}$ in addition to BF } \\
\hline Yes & 453 & 55.2 \\
\hline No & 31 & 3.8 \\
\hline \multicolumn{3}{|c|}{ Frequency of feeding/day } \\
\hline$<3$ times & 74 & 9.0 \\
\hline 3times & 227 & 27.7 \\
\hline$>3$ times & 152 & 18.5 \\
\hline \multicolumn{3}{|c|}{ Method of feeding } \\
\hline Bottle & 8 & 1.0 \\
\hline Cup & 230 & 28.0 \\
\hline Spoon & 187 & 22.8 \\
\hline Hand & 28 & 3.4 \\
\hline \multicolumn{3}{|c|}{ EBF child( In months) } \\
\hline $1-3$ & 11 & 1.3 \\
\hline $4-5$ & 27 & 3.3 \\
\hline 6 & 770 & 93.9 \\
\hline $7-12$ & 12 & 1.5 \\
\hline \multicolumn{3}{|l|}{ Immunization } \\
\hline Yes & 785 & 95.7 \\
\hline No & 35 & 4.3 \\
\hline \multicolumn{3}{|c|}{ Vitamin A supplementation } \\
\hline Yes & 766 & 93.4 \\
\hline No & 54 & 6.6 \\
\hline
\end{tabular}

Table 3: Characteristics of caring practice of children age 6-59 months of Hidabu Abote district, North shewa zone, Oromia, September 2012( $n=820)$. 
Citation: Mengistu K, Alemu K, Destaw B (2013) Prevalence of Malnutrition and Associated Factors Among Children Aged 6-59 Months at Hidabu Abote District, North Shewa, Oromia Regional State. J Nutr Disorders Ther T1: 001. doi:10.4172/2161-0509.T1-001

Page 9 of 15

Almost 630(77\%) of mothers did not take extra food during pregnancy or lactation. About 685(84) \%of mothers visited health facilities for ANC during pregnancy of study subjects. Regarding the use of family planning, 672(82\%) mothers were used family planning and such Depo-Provera633 (77.2\%) were used by majority of the mothers.

\section{Environmental Health Characteristics of Households}

The main sources of drinking water used by households, 533(65\%) public tap and unprotected spring water 232(28.3\%). River and protected spring water also sources of drinking water (Figure 3 ).

Almost 722 (88\%) of households require greater than 30 minutes fetching water from these sources (Table 5). Water used per house per day, 412(50.2\%) HHs were used less than 40 liters and 352(42.9\%) were used 40-60 liter per day (Table 5).

With regarding to treating drinking water in households, majority of HHs (594)72.4\%were treat water to make it safe to drink. Concerning about toilet facilities, Majority of households 598(73\%) had latrine. In this study district, wooden slap of latrine is the most commonly being utilized and almost all households were wash hand after toilet, especially by using soap 669(82\%).Regarding waste disposal system, $305(37 \%)$ and $278(34 \%)$ households were dispose garbage in a pit and open field, respectively.

\section{Prevalence of Malnutrition Among Children Aged 6-59} Months

The overall prevalence of malnutrition of children among aged 6 -

\begin{tabular}{|c|c|c|}
\hline Characteristics & Frequency & Percent \\
\hline \multicolumn{3}{|l|}{ Age of mother(years) } \\
\hline $15-19$ & 22 & 2.7 \\
\hline $20-29$ & 459 & 56.0 \\
\hline $30-39$ & 291 & 35.5 \\
\hline $40-49$ & 48 & 5.9 \\
\hline \multicolumn{3}{|l|}{ Age at first birth(years) } \\
\hline$<15$ & 4 & 0.5 \\
\hline $15-19.8$ & 110 & 13.4 \\
\hline $20-29.8$ & 512 & 62.4 \\
\hline $30-39.5$ & 167 & 20.4 \\
\hline $40-49$ & 27 & 3.3 \\
\hline \multicolumn{3}{|l|}{ Total child born before } \\
\hline No & 151 & 18.4 \\
\hline $1-3$ & 419 & 51.1 \\
\hline $4-6$ & 214 & 26.1 \\
\hline$>7$ & 36 & 4.4 \\
\hline \multicolumn{3}{|c|}{ Extra food during pregnancy/lactation } \\
\hline Yes & 190 & 23.2 \\
\hline No & 630 & 76.8 \\
\hline \multicolumn{3}{|l|}{ Visit health facility for ANC } \\
\hline Yes & 685 & 83.5 \\
\hline No & 135 & 16.5 \\
\hline \multicolumn{3}{|l|}{ Family planning used ${ }^{b}$} \\
\hline Yes & 685 & 82.0 \\
\hline No & 71 & 8.7 \\
\hline \multicolumn{3}{|l|}{ Types of family planning used } \\
\hline Pills & 27 & 3.3 \\
\hline Depo-Provera & 633 & 77.2 \\
\hline Others $^{a}$ & 12 & 1.5 \\
\hline
\end{tabular}

a=Norplant, condom and calendar methods

Table 4: Maternal characteristics of Hidabu Abote district, North shewa zone, Oromia, September 2012 $(n=820)$.

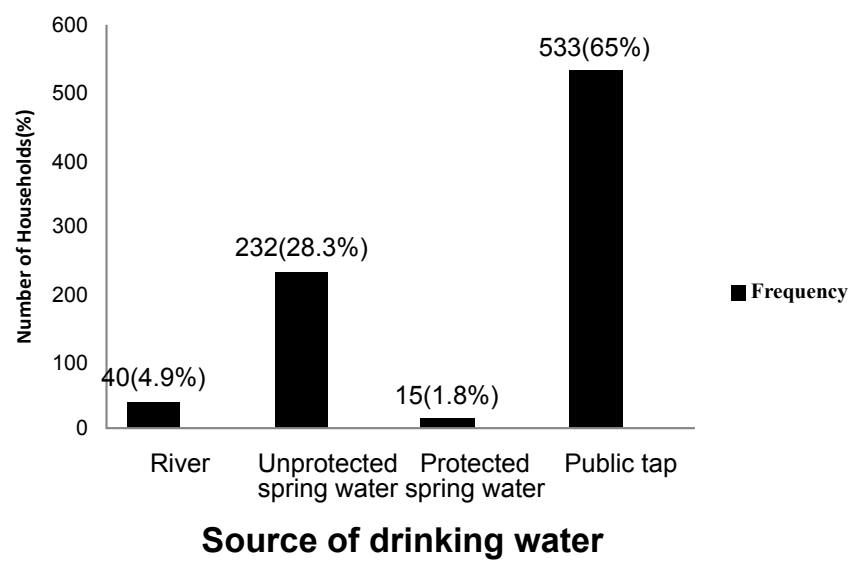

Figure 3: Main source of drinking water of households at Hidabu Abote district, North Shewa, Oromia, September 2012.

\begin{tabular}{|c|c|c|}
\hline Characteristics & Frequency & Percent \\
\hline \multicolumn{3}{|c|}{ Water used in HH per day by liters } \\
\hline$<40$ & 412 & 50.2 \\
\hline $40-80$ & 352 & 42.9 \\
\hline$>80$ & 56 & 6.8 \\
\hline \multicolumn{3}{|c|}{ Time to obtain drinking water (round trip) } \\
\hline$<15$ minutes & 587 & 71.6 \\
\hline 15-30minutes & 201 & 24.5 \\
\hline$>30$ minutes & 32 & 3.9 \\
\hline \multicolumn{3}{|l|}{ HHs treat water by any means ${ }^{R}$} \\
\hline Yes & 594 & 72.4 \\
\hline No & 226 & 27.6 \\
\hline \multicolumn{3}{|l|}{ Availability of latrine } \\
\hline Yes & 598 & 72.9 \\
\hline No & 222 & 27.1 \\
\hline \multicolumn{3}{|c|}{ Materials used to wash hands after toilet } \\
\hline Using water only & 50 & 6.1 \\
\hline Using soap sometimes & 669 & 81.6 \\
\hline Using soap always & 101 & 12.3 \\
\hline \multicolumn{3}{|l|}{ Method of disposal of HHs waste } \\
\hline Open field disposal & 278 & 33.9 \\
\hline In a pit & 305 & 37.7 \\
\hline Common pit & 19 & 2.3 \\
\hline Composing & 211 & 25.7 \\
\hline Burning & 7 & 0.9 \\
\hline
\end{tabular}

Note: ${ }^{\mathrm{R}}$ boiling, bleaching, straiting with cloth

Table 5: Environmental Health characteristics of household of Hidabu Abote district, North shewa zone, Oromia, September 2012(n=820).

59 months in study area were $47.6 \%$ stunted, $30.9 \%$ were underweight and $16.8 \%$ were wasted. The highest prevalence of malnutrition children aged 6-59 months were seen in male (Figure 4).

Compared with age groups, the highest prevalence of stunting was children age 24-35 months followed by children aged 12-23 month. However, the lowest prevalence of stunting was seen in children aged 6-11 months as indicated below (Figure 5).

As indicated in figure 6, the highest prevalence of underweight was seen children aged $48-59$ months with prevalence of $8 \%$.However, the lowest prevalence of underweight seen children aged 6-11 months with prevalence of $1.7 \%$. 
The highest prevalence of wasting was seen children aged 48 59 months at Hidabu Abote district with 5\%prevalence.The lowest prevalence of wasting was seen in children aged 6-11 months (Figure 7).

\section{Factors Associated with Malnutrition of Children}

Associated factors of stunting: Based on the multivariate regression analysis of this study, child age, family monthly income, mothers those used family planning and children who were received butter pre-lacteal were significantly associated chronic malnutrition (stunting). Children age group 13-24 months were about 7 times more likely to be stunted than children age 6-11 months(AOR=7.15; 95\% CI $=2.33,21.90$ ) (Table 6).

Another association found in this study result, children those family monthly income 750-1000birr were less likely to be stunted than children whose family monthly income were less than 750 birr $(\mathrm{AOR}=0.24 ; 95 \% \mathrm{CI}=0.11,0.51)$.

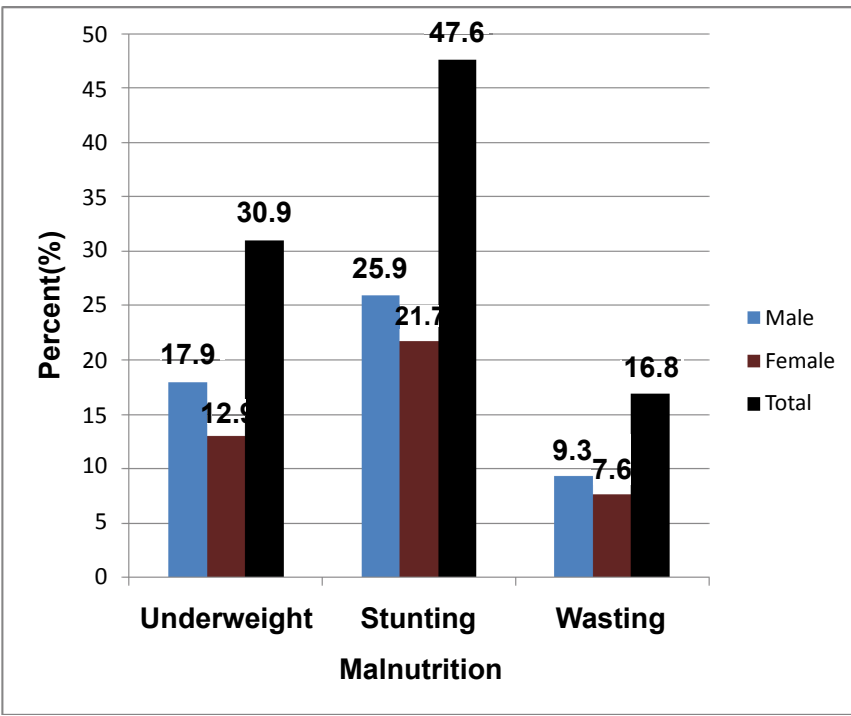

Figure 4: Distribution of malnutrition among children aged 6-59 months by sex at Hidabu Abote district, North Shewa, Oromia, September 2012.

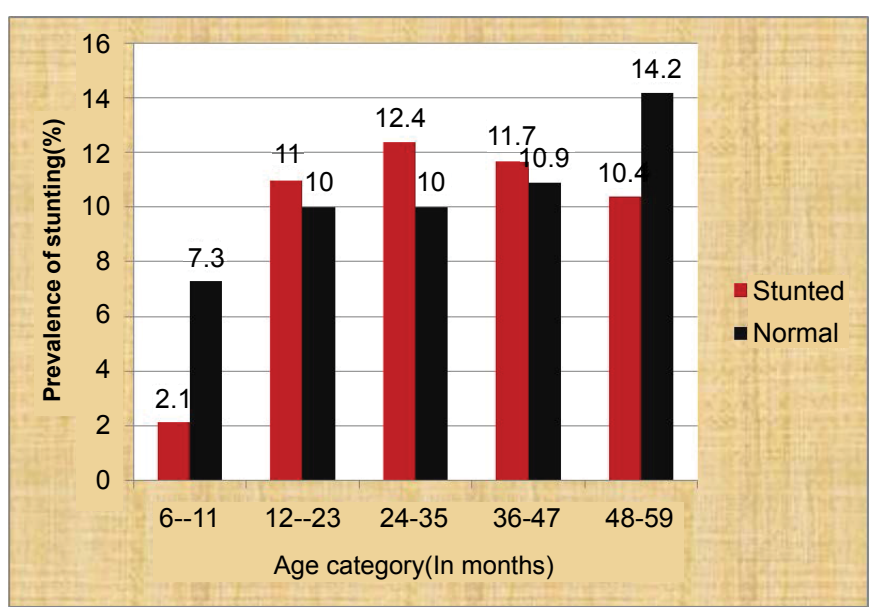

Figure5: Prevalence of stunting by age among children aged 6-59 months at Hidabu Abote District, North Shewa, Oromia, September 2012.

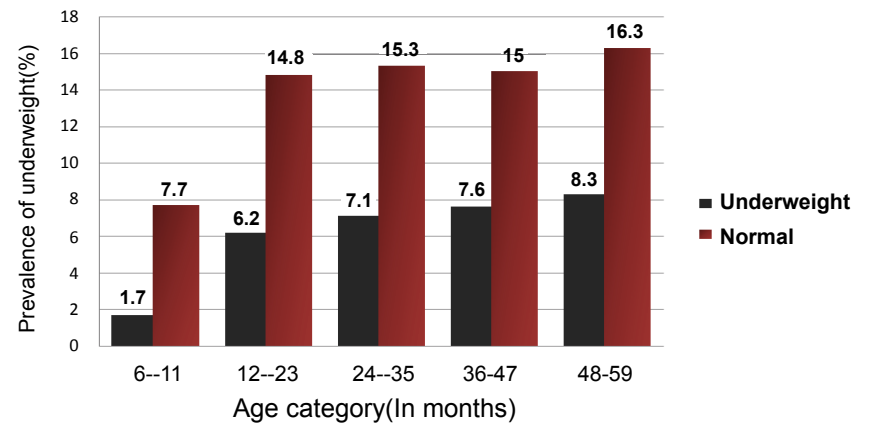

Figure 6: Prevalence of underweight by age among children aged 6-59 months at Hidabu Abote district, North Shewa, Oromia, September 2012.

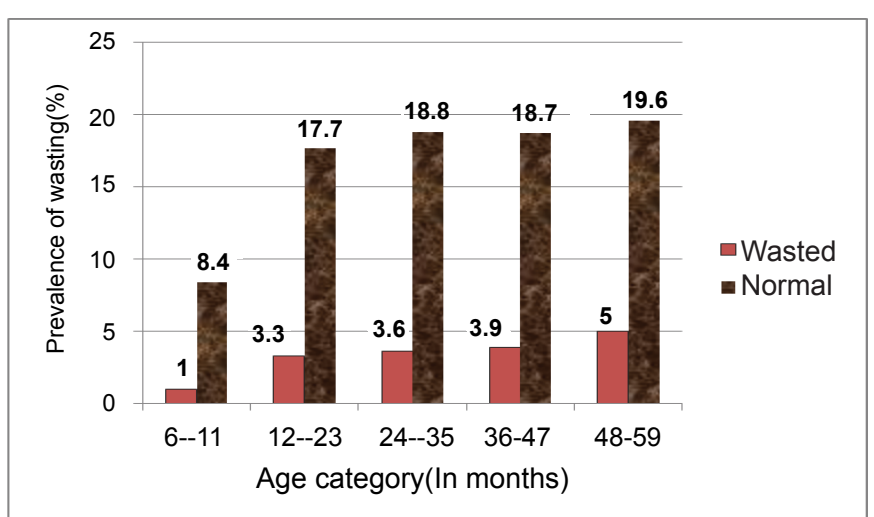

Figure 7: Prevalence of wasting by age among children aged 6-59 months at Hidabu Abote, North Shewa, Oromia, September 2012.

This study result also revealed that, children whose mothers were not used family planning were found 2.54 times more likely to be stunted as compared to children whose mothers were used family planning at district $(\mathrm{AOR}=2.54 ; 95 \% \mathrm{CI}=1.12,5.77)$.

Regarding the association of pre-lacteal feeding with stunting, children who were fed butter as pre-lacteal feeding were about 3 times more likely to be stunted compared to children who received water with sugar by their mothers/care taker $(\mathrm{AOR}=3.102 ; 95 \% \mathrm{CI}=1.82,5.31)$.

Unlike others study, this result showed that, sex of child, family size, and maternal education status, ownership of farm land, diarrhea and time to obtain drinking water (round trip) were not statically associated with stunting by multivariate analysis.

Associated factors of underweight: As indicated Table 7, total number of under five were living in HHs and Kind of floods/fluids children were received as pre-lacteal feeding were significantly associated with underweight in final multivariate analysis.

Analysis of this study showed that, children comes from those family had three under five children in $\mathrm{HHs}$ were about 4.5 times more likely underweight as compared to those children were come from family had one under five children ( $\mathrm{AOR}=4.52 ; 95 \% \mathrm{CI}=1,01,20.23)$. Although this result reveled that, children who received butter as pre-lacteal feeding were about 2 times more likely underweight as compared to those were received water with sugar as per-lacteal feeding (AOR=1.94;95\%CI=1.38,3.31) (Table 7).

Associated factors of wasting: Table 8 show that, treatment of water at $\mathrm{HHs}$ level was the only variable significantly associated with 
Citation: Mengistu K, Alemu K, Destaw B (2013) Prevalence of Malnutrition and Associated Factors Among Children Aged 6-59 Months at Hidabu Abote District, North Shewa, Oromia Regional State. J Nutr Disorders Ther T1: 001. doi:10.4172/2161-0509.T1-001

Page 11 of 15

malnutrition as measured by wasting. Children who were from those family not treat water by any means (boiling, straining, bleaching) 2.4 times more likely wasted as compared to children who were from those family treat drinking water obtained from river and unprotected spring water $(\mathrm{AOR}=2.42 ; 95 \% \mathrm{CI}=1.34,4.35)$.

\section{Discussion}

The prevalence of stunting, underweight and wasting were about $47.6 \%), 30.9 \%$ and $16.8 \%$, respectively. The result of this study revealed that, the prevalence of stunting and wasting were higher as compared with a community cross-sectional study conducted in rural kebeles of Haramaya district, $42.2 \%$ stunted and $14.1 \%$ were wasted [25].

Although present study result showed that the prevalence of malnutrition of children aged 6-59 months higher than a study conducted in Gimbi district, Oromia region on 490 children, $32.4 \%$ stunting, $23.5 \%$ underweight and $15.9 \%$ wasting [24].

Finding of this study also revealed that, the prevalence of stunting very high as compared to study conducted on 446 pre-school children aged 0-59 months at Gumbrit, with $24 \%$ prevalence of stunting. However, the prevalence of underweight and wasting were relatively similar, $28.5 \%$ and $17.7 \%$ of children were underweight and wasted, respectively [19].The prevalence of wasting was higher in study district, indicating a serious health problem at the time of data collection as like study conducted on pre-school children of Gumbrit. This might be difference due to study period, study area, age difference of study subject and sample size. In this study, data was collected in September when most rural areas have shortage of food; this could probably one of the reasons for high prevalence of wasting in the area.

Even though the prevalence of underweight very high in this district but lower than study conducted on food Surplus region of Ethiopia in case of West Gojam zone with $49.2 \%$ of children under five were affected by underweight. However, present study showed that prevalence of stunting and wasting were higher as compared with study of west Gojam zone [21]. This may be varies due to socioeconomic, sample size, study subjects and periods as compared with present study.

\begin{tabular}{|c|c|c|c|c|}
\hline \multirow{2}{*}{ Explanatory variables } & \multicolumn{2}{|c|}{ Stunting } & \multirow{2}{*}{$\operatorname{COR}(95 \% \mathrm{Cl})$} & \multirow{2}{*}{ AOR $(95 \% \mathrm{Cl})$} \\
\hline & Yes & No & & \\
\hline \multicolumn{5}{|l|}{ Child sex } \\
\hline Male & 212 & 198 & 1 & \\
\hline Female & 178 & 232 & $0.717(0.544-0.943)^{\star}$ & \\
\hline \multicolumn{5}{|l|}{ Child Age(In months) } \\
\hline 6-11 & 17 & 60 & 1 & 1 \\
\hline $12-23$ & 90 & 82 & $3.874(2.092-7.173)^{+* *}$ & $7.151(2.335-21.902)^{* *}$ \\
\hline $24-35$ & 102 & 82 & $4.390(2.381-8.096)^{+* *+}$ & $6.408(2.137-19.217)^{* *}$ \\
\hline $36-47$ & 96 & 89 & $3.807(2.067-7.013)^{*+*}$ & $3.144(1.081-9.146)^{*}$ \\
\hline $48-59$ & 85 & 117 & $2.564(1.398-4.703)$ & $2.803(0.998-7.877)^{*}$ \\
\hline \multicolumn{5}{|c|}{ Educational status of mother's } \\
\hline Cannot read and write & 275 & 263 & 1 & \\
\hline Can read and write & 6 & 10 & $0.574(0.206-1.601)$ & \\
\hline Primary education & 92 & 123 & $0.715(0.520-0.984)$ & \\
\hline secondary education & 10 & 11 & $0.869(0.363-2.081)$ & \\
\hline Higher education & 7 & 23 & $0.291(0.123-0.690)^{* *}$ & \\
\hline \multicolumn{5}{|c|}{ Family monthly income(In birr) } \\
\hline$<750$ & 330 & 288 & 1 & 1 \\
\hline $750-1000$ & 42 & 72 & $0.509(0.337-0.769)^{* *}$ & $0.236(0.110-0.506)^{\star *+*}$ \\
\hline$>1000$ & 18 & 70 & $0.224(0.131-0.386)^{* * *}$ & $0.133(0.033-0.543)^{* *}$ \\
\hline \multicolumn{5}{|l|}{ Ownership of farm land } \\
\hline Yes & 222 & 274 & 1 & \\
\hline No & 168 & 156 & $1.329(1.004-1.760)^{*}$ & \\
\hline \multicolumn{5}{|l|}{ Gestational age } \\
\hline less than 9 months & 21 & 12 & 1 & \\
\hline At 9 months & 274 & 275 & $0.569(0.275-1.180)$ & \\
\hline Greater than 9 months & 95 & 143 & $0.380(0.178-0.808)^{* *}$ & \\
\hline \multicolumn{5}{|l|}{ Use of family planning } \\
\hline Yes & 311 & 361 & 1 & 1 \\
\hline No & 39 & 32 & $1.415(0.865-2.2 .313)$ & $2.543(1.121-5.767)^{\star}$ \\
\hline \multicolumn{5}{|c|}{ Pre-lactation Foods/fluids } \\
\hline Water with sugar & 45 & 80 & 1 & 1 \\
\hline Butter & 139 & 108 & $2.288(1.469-3.565)^{+* t+}$ & $3.102(1.815-5.305)^{+* *}$ \\
\hline \multicolumn{5}{|c|}{ Time to obtain drinking water (round trip) } \\
\hline$<15$ minutes & 296 & 291 & 1 & \\
\hline 15-30minutes & 83 & 118 & $0.692(0.500-0.956)^{*}$ & \\
\hline$>30$ minutes & 11 & 21 & $0.515(0.244-1.087)$ & \\
\hline
\end{tabular}

Note ${ }^{*}=\mathrm{p}<0.05,{ }^{* *}=P<0.01,{ }^{* * *}=P<0.001$

Backward LR Used in multivariate analysis

Table 6: Bivariate and multivariate analysis showing impact of selected independent variables on stunting among children age 6-59 months at Hidabu Abote district, North Shewa, Oromia, September 2012( $(n=820)$. 
Citation: Mengistu K, Alemu K, Destaw B (2013) Prevalence of Malnutrition and Associated Factors Among Children Aged 6-59 Months at Hidabu Abote District, North Shewa, Oromia Regional State. J Nutr Disorders Ther T1: 001. doi:10.4172/2161-0509.T1-001

\begin{tabular}{|c|c|c|c|c|}
\hline \multirow{2}{*}{ Explanatory variables } & \multicolumn{2}{|c|}{ Underweight } & \multirow{2}{*}{ COR $95 \% \mathrm{Cl}$} & \multirow{2}{*}{ AOR $95 \% \mathrm{Cl}$} \\
\hline & Yes & No & & \\
\hline \multicolumn{5}{|l|}{ Child sex } \\
\hline Male & 147 & 263 & 1 & \\
\hline Female & 106 & 304 & $0.624(0.462-0.842)^{*}$ & \\
\hline \multicolumn{5}{|c|}{ Total under five children in HHs } \\
\hline 1 & 186 & 449 & 1 & 1 \\
\hline 2 & 61 & 106 & $1.389(0.971-1.988)$ & 1.871(1.048-3.39) \\
\hline 3 & 6 & 12 & $1.207(0.446-4.264)$ & $4.517(1.008-20.233)^{\star}$ \\
\hline \multicolumn{5}{|c|}{ Occupational status of father } \\
\hline Farmer & 176 & 409 & 1 & \\
\hline Gov't employee & 12 & 48 & $0.581(0.301-1.120)$ & \\
\hline Merchant/Trade & 30 & 71 & $0.982(0.619-1.558)$ & \\
\hline Others & 35 & 39 & $2.086(1.278-3.402)^{*}$ & \\
\hline \multicolumn{5}{|l|}{ Ownership of livestock's } \\
\hline Yes & 159 & 403 & 1 & \\
\hline No & 94 & 164 & $1.453(1.062-1.987)^{\star}$ & \\
\hline \multicolumn{5}{|l|}{ Place of delivery } \\
\hline Home & 213 & 439 & 1 & \\
\hline Health facility & 40 & 128 & $0.644(0.436-0.952)^{\star}$ & \\
\hline \multicolumn{5}{|c|}{ Kinds of foods/fluids as pre-lacteal } \\
\hline Water with sugar & 24 & 101 & 1 & 1 \\
\hline Butter & 84 & 163 & $2.169(1.23-3.637)^{* *}$ & $1.941(1.138-3.310)^{\star}$ \\
\hline \multicolumn{5}{|c|}{ Treat drinking water in home by any means } \\
\hline Yes & 168 & 426 & 1 & \\
\hline No & 85 & 141 & $1.529(1.107-2.111)^{*}$ & \\
\hline \multicolumn{5}{|l|}{ Availability of latrine } \\
\hline Yes & 170 & 428 & 1 & \\
\hline No & 83 & 139 & $1.503(1.086-2.080)^{\star}$ & \\
\hline
\end{tabular}

Note, ${ }^{* * *} \mathrm{p}<0.001, \quad{ }^{* *} \mathrm{P}<0.01, \quad{ }^{*} \mathrm{P}<0.05$

Backward LR used in multivariate analysis

Table 7: Bivariate and multivariate analysis showing impact of selected independent variables on Underweight among children age 6-59 months at Hidabu Abote district, North Shewa, Oromia, September 2012( $(n=820)$.

\begin{tabular}{|c|c|c|c|c|}
\hline \multirow{2}{*}{ Explanatory variables } & \multicolumn{2}{|c|}{ Wasting } & \multirow{2}{*}{ COR $95 \% \mathrm{Cl}$} & \multirow{2}{*}{ AOR $95 \% \mathrm{Cl}$} \\
\hline & Yes & No & & \\
\hline \multicolumn{5}{|l|}{ Child sex } \\
\hline Male & 76 & 334 & 1 & \\
\hline Female & 62 & 348 & $0.783(0.542-1.131)$ & \\
\hline \multicolumn{5}{|l|}{ Ownership of livestock } \\
\hline Yes & 85 & 477 & 1 & \\
\hline No & 53 & 205 & $1.451(0.992-2.122)$ & \\
\hline \multicolumn{5}{|l|}{ Immunization } \\
\hline Yes & 129 & 656 & 1 & \\
\hline No & 9 & 26 & $1.760(0.806-3.844)$ & \\
\hline \multicolumn{5}{|l|}{ Presence of Fever } \\
\hline Yes & 14 & 41 & 1 & \\
\hline No & 124 & 641 & $0.567(0.300-1.071)$ & \\
\hline \multicolumn{5}{|l|}{ Initiation of breastfeeding } \\
\hline Immediate after birth & 81 & 465 & 1 & \\
\hline After 1 to $24 \mathrm{hrs}$ & 2 & 20 & $0.574(0.132-2.503)$ & \\
\hline After a day & 55 & 197 & $1.603(1.095-2.346)^{*}$ & \\
\hline \multicolumn{5}{|c|}{ Kinds of foods/fluids as pre-lacteal feeding } \\
\hline Water with sugar & 14 & 111 & 1 & \\
\hline Butter & 51 & 196 & 2.063(1.093-3.3.895) & \\
\hline \multicolumn{5}{|c|}{ Treatment of drinking water by any means ${ }^{a}$} \\
\hline Yes & 81 & 513 & 1 & 1 \\
\hline No & 57 & 169 & $2.136(1.460-3.126)^{*+*}$ & $2.416(1.343-4.347)^{*+*}$ \\
\hline \multicolumn{5}{|l|}{ Available of latrine } \\
\hline Yes & 91 & 507 & 1 & \\
\hline No & 47 & 175 & $1.496(1.011-2.214)^{\star}$ & \\
\hline
\end{tabular}

Note ${ }^{* * *} p<0.001,{ }^{*} p<0.01,{ }^{*} \mathrm{P}<0.05 \quad a$ a $=$ boiling, bleaching, Straining with cloth

Backward LR used in multivariate analysis

Table 8: Bivariate and multivariate analysis showing impact of selected independent variables on wasting among children age 6-59 months at Hidabu Abote district, North Shewa, Oromia, September 2012 $(n=820)$ 
Prevalence of malnutrition also higher than cross-section study conducted on Beta-Israel children in Amhara region, 37.2\%, $14.6 \%$ and $4.9 \%$ of children age $0-59$ months were stunted, underweight and wasted, respectively [20]. The prevalence of malnutrition increased as age increases.

As showed in this study result, the prevalence of malnutrition among children age 6-59 months were also higher than EDHS 2011 National report, $44 \%$ stunted, $29 \%$ underweight and $10 \%$ wasted. Also this study result revealed that, prevalence of malnutrition higher than that of Oromia regional state reported in the national, $41.4 \%$ stunting, $26 \%$ underweight and $9.7 \%$ wasting [6].

Prevalence of stunting higher but prevalence of underweight was low as compared to study done in Bangladesh, $42 \%$ and $40 \%$ of children were stunted and underweight, respectively [13]. Although the prevalence of malnutrition higher in this finding as compared to study conducted in Mongolia, the prevalence of stunting, wasting and underweight were $15.6 \%, 1.7 \%$ and $4.7 \%$, respectively [14]. This might be difference also due to study period, socioeconomic characteristics, health service delivery, study area and age difference.

The prevalence wasting in this study was low as compared to study conducted in Southern Sudan; approximately one out of every five children (22\%) suffers wasting. Study conducted in a decertified area of Sudan - Alrawakeeb valley, $27.5 \%$ were severely malnourished and $35 \%$ suffered from either mild or moderate malnutrition $[16,17]$. This may be difference also probable due study period, study area, socioeconomic characteristic, health service delivery, and geographical characteristics of study area.

Result also revealed that prevalence of malnutrition higher than a cross-sectional comparative study conducted in Belahara VDC of Dhankuta district in Nepal located in South Asia, the prevalence of underweight, stunting and wasting was $27 \%, 37 \%$ and 11 , respectively [15].

Regarding associated factors of malnutrition, analysis of this study indicated child age, family monthly income, use of family planning were found to be significantly associated with Stunting.

Present finding revealed that, family monthly income strongly negative association with stunting. This result was consistent with study conducted rural community in rural kebeles of Haramaya district [25]. As the family income was increased, the level of chronic malnutrition among children aged 6-59 months also decreased as like other studies in developing countries and here in Ethiopia [15,17,25]. Present study indicate that children from whose family monthly income 750-1000birr were less likely affected by stunting as compared to children those family monthly income less than 750 birr(AOR $=0.24$; $95 \% \mathrm{CI}=0.11,0.51)$.

Family/household income was significantly associated with nutritional status of the under five children. Children belonging to the low-income group were at a higher risk of being wasted, underweight and stunted than children of better income families. Although the economic differentials seem to be silent in rural society it appears to be an important predictor of childhood nutritional status. Low income levels of developing nation limits the kinds and the amounts of food available for consumption. Low income also increases the likelihood of infection through such mechanisms as inadequate personal and environmental hygiene [19].

The present findings also showed that, children aged 12-23 months were 7 times more likely affected by stunting as compared to children were aged 6-11 months. This result consistent with other studies conducted in Ethiopia and other developing countries, which showed the prevalence of stunting positively associated with child age $[14,20,21,22]$. As result indicated on descriptive, the prevalence of Child malnutrition increased with age. It appears that both chronic and acute child malnutrition, develop during the weaning period and rise sharply thereafter. The national EDH 2011 national also indicated that, the prevalence of stunting increases as the age of child increases consistent [6]. The prevalence of diseases and stunting rises with age [31].

Although this study showed that, children were received butter as pre-lacteal feeding was positively associated with the occurrences of stunting and underweight. Children who were received butter as pre-lacteal feeding 3 times more likely affected by stunting as compared to those who were received water with sugar [AOR=3.102;95\%CI $=1.815,5.305]$. Children who were received butter were about 2 times more likely to be underweight as compared to children who were received sugar with water $[\mathrm{AOR}=1.94 ; 95 \% \mathrm{CI}=1.14$, 3.31]. Study conducted at western Gojam Zone revealed that, higher proportion of children who were received pre-lacteal feeding $(48.3 \%)$ were stunted as compared to children who were not given fed pre-lacteal feeding by their mothers or care takers [21]. Another study conducted in Northern part of Tigray region reveled that, the commonly used pre-lacteal foods were butter (46.7\%), sugar dissolved in water (15.1\%) and plain water (14.5\%) [22]. However, in present study indicated on descriptive parts, 372(45.4\%) children were received pre-lacteal feeding. According to EDHS 2011 national report, nearly three children in every ten ( 27 percent) are given pre-lacteal feeds within the first three days of life. The practice of giving pre-lacteal feeds is discouraged because it limits the infant's frequency of suckling and exposes the baby to the risk of infection and malnutrition [6].

The present study also showed that, children whose mother were not using family planning were about 2.5 times more likely to be stunted as compared to those who were used family planning $(\mathrm{AOR}=2.54$ $95 \% \mathrm{CI}=1.121,5.767)$. Even though birth interval was not included in study as independent variables, family planning was used for birth spacing. This indicated that children born from mother who had been using birth spacing were less likely affected by stunting.

According to this study finding, having more under five children in households and children were received butter as per-lacteal feeding immediately after birth were significantly associated with underweight.

As indicated in this study result, children were from those family had three under five children were about 4.5 times more likely affected by underweight as compared to those from family had one under five children $[\mathrm{AOR}=4.52 ; 95 \% \mathrm{CI}=1.01,20.33]$. This study similar with study conducted in an urban slum of Ludhiana showed that, the prevalence of underweight was found to be significantly higher in those with more siblings. Those with no siblings, had the lowest proportion of underweight children (12.8\%), higher in those with 1-2 siblings (30.6\%) and highest (51.7\%) in those with more than three siblings [31]. The prevalence of underweight found to increasing as the number of sibling increasing because of having more children below five years of age might be more difficulty in caring for children.

Present study showed that, children from family not treat their drinking water by boiling, straining through cloth and bleaching/ chlorine were more likely affected by wasting as compared to children were from family treat their drinking water. This finding similar to study conducted western Kenya showed that, more children who drank water that was not consistently treated in households were 
wasted [32]. An overwhelming majority, nine households in every ten, do not treat their drinking water. Rural households are not use an appropriate treatment method to ensure that water is safe for drinking as compared to urban [6]. Therefore, diarrhea and water born diseases caused by unsafe drinking water at households' level might be increase the prevalence of malnutrition directly or indirectly.

Education is one of the most important resources that enable women to provide appropriate care for their children. Education of women is believed to exert an impact on health and nutritional status of children since it provides the mother with the necessary skills for child care, increase awareness of nutritional needs and preference of modern health facilities as well as change of traditional beliefs about diseases causation, and use of contraceptives for birth spacing [27]. In this study result, majority of mothers or care takers were can't read and write but significance association was not found with prevalence of malnutrition.

\section{Limitation of Study}

- The prevalence of wasting during the present study was very high as compared to others study. This might be due to difficulty of entertaining the seasonal variation, because study was conducted during summer season when the shortages of foods happen at community level.

- Others significant independent variables did not included like birth interval, weight at birth, MBI.

- Recall bias

\section{Conclusions and Recommendations}

\section{Conclusions}

This study revealed that, prevalence of malnutrition was high and it was the top list among the health problems in Hidabu Abote district. The prevalence statistics in this study area were higher than the regional and national figures found from Ethiopian Demographic Health Survey 2011 national reports.

According to investigation of independent variables with dependent variables in multivariate analysis, child age, family monthly income, kinds of pre-lacteal feeding and family planning were significance association with chronic malnutrition. However, having more under five children in household and children were received butter as perlacteal feeding were associated with underweight. Households not treat their drinking water was the only variables associated with wasting among children were aged 6-59 months in district.

\section{Recommendations}

$>$ Community based nutrition program should be established to tackle the problem of malnutrition at community level depending on the severity of malnutrition identified in this study.

$>$ Nutrition education by health extension works should be strengthening to improving the feeding practice of parents on appropriate children feeding.

$>$ Continued attention should mandatory to infant exclusive breast feeding practices till 6 months is important to avoid traditionally giving butter as pre-lacteal feeding by rural community.

Woreda health office should be collaborated with others sectors and stake holders to improve access of water supply.
> Households should be treat drinking water which obtained from unprotected spring water and river by boiling, bleaching and strained through cloth

> Woreda administration should strengthen and established income generation active and saving at households like credit and saving process with collaborate of stake holders to improve family income.

$>$ Use of family planning should be encourage at community level

$>$ Further study should be done to see other an explored associated factors that were not included in the present study.

$>$ Nutrition surveillance needs to be done continuously and special attention should be given to vulnerable groups such as poorest and the most severely malnourished children.

\section{Acknowledgement}

I would like to express my heartfelt gratitude to my advisors Mr. Kassahun Alemu (BSc, MPH) and Mr. Bikes Destaw (BSc, MPH) for their valuable and unreserved comments starting from proposal to the final paper

My deeply thanks go to CSA for supporting anthropometric tools during data collection. Also, I would like to thanks University of Gondar financial support.

My thanks go to FMOH, ORHB, North shewa health department, Ejere woreda health office, Kebele administration, HEWs, study participants, supervisor and data collectors supporting me and unreserved cooperation during data collection.

I really would like to express my deep gratitude and appreciation to my mother, Mama your prayers are always a source of strength. I am deeply indebted to her for her patience, concern and love. Also, I would like to thank my brother (Sime Mengistu), Sister (Lomi) and my wife (Tigist Abebe) for their support.

Finally, I would like to extend my appreciation to relatives (Tamiru B, Ashabir, Yosef, and Hunda'ol) and my friends (Birara, Tsegazaeb, Tamiru Tadesse) for their great help.

\section{References}

1. Müller $O$, Krawinkel M (2005) Malnutrition and health in developing countries. CMAJ 173: 279-286.

2. Black RE, Morris SS, Bryce $\mathrm{J}$ (2003) Where and why are 10 million children dying every year? Lancet 361: 2226-2234.

3. de Onis M, Blössner M, Borghi E, Frongillo EA, Morris R (2004) Estimates of global prevalence of childhood underweight in 1990 and 2015. JAMA 291: 2600-2606.

4. Reed BA, Habicht JP, Niameogo C (1996) The effects of maternal education on child nutritional status depend on socio-environmental conditions. Int $\mathrm{J}$ Epidemiol 25: 585-592.

5. Alemu M, Nicola J, Belele T (2005) Tackling child malnutrition in Ethiopia; Young lives project working paper No 19; Save the children UK 26.

6. Ethiopian DHS 2011, Central Statistical Agency, Addis Ababa, Ethiopia; September 2006:19-20.

7. The State of the World's Children (2005) A UNICEF REPORT: Childhood under threat.

8. Caulfield LE, de Onis M, Blössner M, Black RE (2004) Undernutrition as an underlying cause of child deaths associated with diarrhea, pneumonia, malaria, and measles. Am J Clin Nutr 80: 193-198.

9. de Onis M, Frongillo EA, Blössner M (2000) Is malnutrition declining? An analysis of changes in levels of child malnutrition since 1980. Bull World Health Organ 78: 1222-1233.

10. Armstrong J, Dorosty AR, Reilly JJ, Emmett PM; Child Health Information Team (2003) Coexistence of social inequalities in undernutrition and obesity in preschool children: population based cross sectional study. Arch Dis Child 88: 671-675.

11. Senbanjo IO, Adeodu OO, Adejuyigbe EA (2009) Influence of socio-economic factors on nutritional status of children in a rural community of Osun State, Nigeria. 
Citation: Mengistu K, Alemu K, Destaw B (2013) Prevalence of Malnutrition and Associated Factors Among Children Aged 6-59 Months at Hidabu Abote District, North Shewa, Oromia Regional State. J Nutr Disorders Ther T1: 001. doi:10.4172/2161-0509.T1-001

Page 15 of 15

12. Babatunde RO, Olagunju FI, Fakayode SB, Sola-Ojo FE (2011) Prevalence and determinants of Malnutrition among Under-five Children of Farming Households in Kwara State, Nigeria. Journal of Agricultural Science 3: 173-181.

13. Siddiqi NA, Haque N, Goni MA (2011) Malnutrition of Under-Five Children Evidence from Bangladesh. Asian Journal of Medical Sciences 2: 113-118.

14. Otgonjargal D, Bradley A, Woodruff F, Batjarga I, Davaalkham D (2012) Nutritional status of under- five children in Mongolia. Journal of Medicine and Medical Sciences 3: 341-349.

15. Sapkota VP, Gurung CK (2009) Prevalence and Predictors of Underweight, Stunting and Wasting in Under-Five Children. Nepal Health Res Counc 7: 120126

16. USAID (2007) Nutritional status and its determinants in southern Sudan.

17. Ola E, Ahmed, Mofida Y, et al (2011) Nutritional status of the children under age of five in a decertified area of Sudan - Alrawakeeb valley. International Journal of Current Research 2: 103-108.

18. Kwena AM, Terlouw DJ, de Vlas SJ, Phillips-Howard PA, Hawley WA, et al (2003) Prevalence and severity of malnutrition in pre-school children in a rural area of western Kenya. Am J Trop Med Hyg 68: 94-99.

19. Edris M (2006) Assessment of nutritional status of preschool children of Gumbrit, Ethiop J Health Dev 21: 125-129.

20. Asres G, Eidelman Al (2011) Nutritional assessment of Ethiopian Beta-Israel children: a cross-sectional survey. Breastfeed Med 6: 171-176.

21. Teshome B, Kogi- Makau W, Getahun Z, Taye G (2006) Magnitude and determinants of stunting in children under five years of age in food surplus region of west Gojam zone. Ethiop J Health Dev 23: 98-106.
22. Mulugeta A, Hagos F, Kruseman G, Linderhof V, Stoecker B, et al. (2005) Factors Contributing to Child Malnutrition in Tigray, Northern Ethiopia.

23. Taffesse S, Goitom $L$ (1997) Malnutrition and enteric parasitoses among under five children in Aynalem village of Tigray. Ethiop J Health 14: 67-75.

24. Kebede E (2007)Prevalence and Determinants of Child Malnutrition in Gimbi district 27-39.

25. Zewdu S (2012) Magnitude and Factors Associated with Malnutrition of Children Under Five Years of Age in Rural Kebeles of Haramaya, Ethiopia. Harar Bulletin of Health Sciences 4: 221-232.

26. Yimer G (2000) Malnutrition among children in southern Ethiopia: Levels and risk factors. Ethiopian Journal of Health Development 14: 283-292.

27. Tesfaye M (2009) Bayesian approach to identify predictors of children Nutritional status in Ethiopia.

28. Merrill W (1984) Report of Workshop on income and Nutrition effects of increasing commercialization of semi-subsistence Agriculture. Air lie House Virginia. December 1984: 3-5.

29. Hidabu Abote Health office annual report 2012.

30. http://www.who.int/childgrowth/standards/Technical_report.pdf

31. Paramita S, Nina P, Benjamin Al (2010) Epidemiological correlates of undernutrition in under-5 years children in an urban slum of ludhiana. Health and Population: Perspectives and Issues, 33: 1-19.

32. Emily B, Fidelis W, Robert CB (2002) Prevalence and Predictors of Underweight Stunting, and Wasting among Children Aged 5 and Under in Western Kenya. Journal of Tropical Pediatrics 50: 260-269. 